\title{
El estado de la cuestión sobre la participación política en los jóvenes de la Nación Aymara - Perú. Un diálogo teórico desde sus actores
}

\author{
The state of the question about political participation in the young people \\ of the Aymara-Peru Nation. A theoretical dialogue from its actors
}

\author{
Jesús Wiliam Huanca-Arohuanca ${ }^{11}$ \\ Universidad Nacional de San Agustín de Arequipa, Arequipa, Perú1
}

(iD) ORCID ID: $\underline{\text { https://orcid.org/0000-0002-7353-1166 }}{ }^{1}$

Recibido: 01 de abril de 2021

Aceptado: 15 de agosto de 2021

\begin{abstract}
Resumen
En el contexto desempeñado por el gobierno neoliberal de Alan García Pérez (APRA) y el gobierno de Ollanta Humala Tasso (Partido Nacionalista del Perú), se suscitan las coyunturas electorales regionales de 2014, siendo electos gobiernos con inclinaciones a la tendencia monótona de la experiencia en política, que no garantizan una democracia participativa de los actores jóvenes: AMA, ACESP, CIMA, Huayna Wila y OJICI. En este contexto, el presente trabajo busca interpretar las representaciones sociales juveniles sobre la participación política y los mecanismos de inserción a la política nacional y local. Para ello, se ha empleado una metodología cualitativa, utilizando el grupo de discusión, la entrevista en profundidad y el análisis de discurso como enfoque analítico fundamental. Los partícipes fueron jóvenes líderes representantes que, en algún punto, se sienten desconcertados por la dejadez de la casta política central y periférica de la Nación Aymara (NAM). Se concluye con la afirmación de que los actores jóvenes tienen plena justificación para desplegar políticas públicas dentro del gobierno central y los umbrales afines a la gobernabilidad, pues representan al grupo etario más prospectivo y eficaz.
\end{abstract}

Palabras clave: Representaciones sociales, participación política, organizaciones juveniles, democracia participativa, análisis de discurso, aymara.

Abstract
In the context played by the neoliberal government of Alan García Pérez (APRA) and the
government of Ollanta Humala Tasso (Peruvian Nationalist Party), are aroused the electoral

${ }^{1}$ Correspondencia al autor:

E.mail: jhuancaar@unsa.edu.pe 
junctures regional of 2014, being elect, governments with inclinations to the tendency monotonous of the experience in politics, that they do not guarantee participatory democracy of the actors young: AMA, ACESP, CIMA, Huayna Wila and OJICI. In this contet, the present paper seeks to interpret youth social representations about political participation and the mechanisms of insertion to the national and local politics. Therefore, a qualitative methodology has been used, using the discussion group, the in-depth interview and discourse analysis as a fundamental analytical approach. The participants were young leaders representatives that in some point feel disconcerted by the slovenliness of the central and peripheral political caste of the Nation Aymara (NAM). This study concludes with the statement that young actors have full justification for implementing public policies within the central government and the thresholds related to governability, because they represent the age group more prospective and effective.

Keywords: Social representations, political participation, youth organizations, participatory democracy, discourse analysis, Aymara.

\section{Introducción}

En el foco del siglo XXI, las instituciones existentes resultaron limitadas e incapaces de producir respuestas legítimas frente a las nuevas demandas de la masa de jóvenes que se incorporaban al espacio público de las sociedades nacionales (Misses-Liwerant \& Saracho, 2018). Asimismo, el contexto y el momento en que viven los jóvenes como el entramado que hace posible su configuración relacional; $y$, su diversidad expresiva como potencia transformadora de órdenes instituidos (Arias-Cardona \& Alvarado, 2015) hacen operable un mundo lleno de posibilidades en las cuales los jóvenes repotencien la crítica de la realidad y la reflexión filosófica sin perder el doxa gnoseológico aymara como parámetro educacional (Mansilla \& Piñones-Rivera, 2017).

A partir del cúmulo de sucesos caracterizados por los conflictos sociales y políticos sin cesar en la denominada NAM, los actores jóvenes comprendieron que la única manera de llegar e insertarse en el espacio del gobierno local, es participando como candidatos (Domper-Lasús, 2018). No obstante, los datos que provee la Secretaría Nacional de la Juventud (SENAJU, 2015) no ayudan mucho, debido a que en el 2014 los jóvenes que postularon a las Elecciones Regionales y Municipales (ERM) representaron el 27,8\% del total de candidatos. Esto significa unos 27.276 postulantes jóvenes, de los cuales solo 1.612 resultaron elegidos (5,9\%), que es también el 12,9\% del total de autoridades electas (Galarreta, 2016). Se puede señalar también que, en el actual proceso electoral, ningún 
candidato a gobernador es joven, solo 3\% de candidaturas a vicegobernador son de jóvenes, 28,5\% a consejero y 42\% a accesitario (Urrutia, 2018). En conclusión, los jóvenes son relegados a espacios de menor visibilidad cuando a política formal se refiere.

Para las ERM del año 2014, conformado por jóvenes que representan a más de seis millones setecientos mil electores y electoras, siendo los jóvenes de 18 a 29 años el grupo etario más numeroso del padrón (SENAJU, 2015) hacen pensar en la búsqueda de políticas públicas prospectivas que inserten a ese grupo de 31,5\% del padrón electoral según la misma entidad. Sin embargo, la inserción a la política no puede ser un punto ciego, ya que depende de un factor fundamental denominado, educación. Para Urrutia (2018) el público objetivo de la educación universal (solo 36\% cuenta con educación superior, de los cuales $22 \%$ son universitarios y $14 \%$ estudiantes no universitarios), no es aún una fuerza laboral estable teniendo en cuenta que existen alrededor de 1.5 millones de jóvenes que no estudian ni trabajan.

Cuando se hace un abordaje de las Representaciones Sociales (RS) se hace alusión al fenómeno que forma una serie de percepciones en los actores que deben ser interpretado de manera subjetiva y trascendental. Para Moscovici (1961) la representación es un corpus organizado de conocimientos y una de las actividades psíquicas gracias a las cuales los hombres hacen inteligible la realidad física y social en donde se integran en un grupo o en una relación cotidiana de intercambios, liberando los poderes de su imaginación. Es decir, se puede afirmar que la representación social es una modalidad particular del conocimiento, cuya función es la elaboración de los comportamientos y la comunicación entre los individuos (Mora, 2002).

Para Jodelet (1986), las representaciones constituyen sistemas simbólicos que conforman un modo de construir la realidad y median en la relación sujeto-sociedad. Del mismo modo se construyen en el colectivo, en las relaciones cara a cara, a través del lenguaje en sus diferentes modalidades y/o manifestaciones, que son una manera de interpretar el mundo y, en consecuencia, inclina las actuaciones de los sujetos y los colectivos (NetzahualcoyotlNetzahual, 2015). Consecuentemente, las RS son entidades simbólicas cuyo significado es compartido socialmente y actúan como condicionantes de la acción (Cajas et al., 2017). Así mismo, las RS participan en la definición de la identidad de cada uno de los representantes participantes, salvaguardando la identidad del grupo al que representan (Echeverría et al., 
2017). Por ello, se toma en cuenta el significado que podría adquirir en distintos grupos sociales (García-Espín, Ganuza \& De Marco, 2017) la ciudadanía entendido como juventud. Con el mismo paralelismo, Torres y Lobera (2017) afirman que el análisis pasa por indagar en las imágenes espontáneas que tiene el grupo juvenil respecto a la política local, dado que, más que una inquisición intelectual, espera aportar como actitud hacia la información crítica (Hidalgo et al., 2018) y ser visualizado como una condición social, lo cual implica entender su configuración, en parte, desde la percepción, imaginario, vivencia y caracterización de quienes se definen como jóvenes, Sosteniéndose también que existen formas plurales y heterogéneas de ser joven y actor político enmarcado en el compromiso de aportar a la NAM.

En este sentido, la participación política se debe entender como "tomar parte" de las decisiones políticas en términos gubernamentales resguardados por la Constitución Política del Perú de manera natural y compartida. Es decir, la participación política viene a ser la suscripción de ciudadanos, instituciones y organizaciones políticas en un proceso democrático. No obstante, la participación política juvenil va más allá de la "participación electoral", en otras palabras, no se limita con el simple suceso de ir a las urnas. Puesto que, cuando se habla de participación ciudadana, se tiene que ir más allá de las actitudes favorables o contrarias, ya que, las organizaciones juveniles manejan concepciones distintas (GarcíaEspín, Ganuza \& De Marco, 2017) más aun, cuando se habla de la participación política enmarcado en un contexto de la ecuación emancipatoria de la juventud Aymara.

La participación política obedece a cuatro principios fundamentales formulados por Bobbio y Manin sustentados por la (Oficina Nacional de Procesos Electorales (ONPE), 2017) en donde el primer principio abarca sobre que quienes gobiernan son elegidos a través de las elecciones por periodos regulares. El segundo principio explica, la toma de decisiones realizados por los gobernantes salvaguardando su independencia, en cierta medida, en comparación con los deseos del electorado. El tercer principio asume que los gobernados son libres de expresar sus sentimientos políticos sin temor al control de los gobernantes. Por último, el cuarto principio manifiesta que las decisiones públicas requieren un proceso de debate previo. Está claro, que, si los jóvenes no consiguen acceder al primer principio los que vienen son distantes a materializarse.

Uno de los desafíos fundamentales que tiene la humanidad es: reforzar la relación entre el Estado y la juventud para restablecer la confianza en las instituciones (Centro de Desarrollo 
de la OCDE, 2017). Ya que, las escasas vías de participación institucional activadas fueron de baja calidad y mostraron sus limitaciones en términos de representatividad, legitimidad y de la promoción de una participación ciudadana que resultará útil al propio desarrollo del proyecto (Díaz, 2018) entendido como gestión moderna de la «cosa pública», sobre la base de un territorio determinado, que requiere actores involucrados de manera efectiva (Flores, 2017).

En cuanto a estadísticas se trata los datos hablan por sí mismos, debido a que el presupuesto inicial de apertura dirigido a la niñez y adolescencia se aceleró en 2015, creciendo la tasa del presupuesto referido al sector público en (10\%), hasta alcanzar S/. 24 millones, lo que equivale al 23\% del presupuesto público total (Arias, 2015).

\section{Gráfico 1}

Presupuesto de apertura 2013-2015 (Millones de nuevos soles).

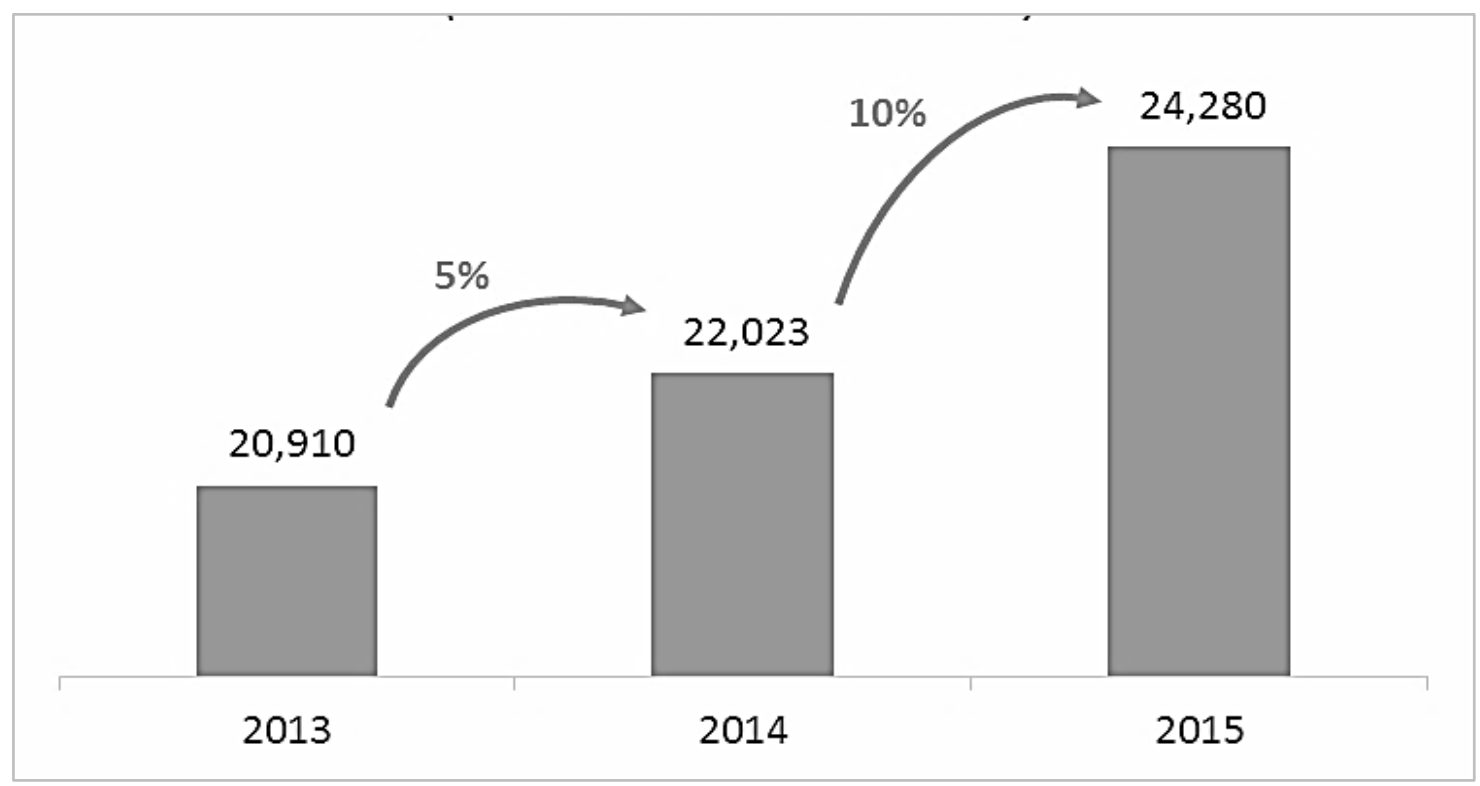

Fuente: MEF - SIAF, con información al 5 de mayo de 2015.

Elaboración: MEF - Dirección General de Presupuesto Público.

Mientras que, los presupuestos destinados a los espacios institucionalizados para adelantar políticas públicas y atender a las poblaciones juveniles (Consejos de Juventud, Institutos de Juventud, Casas de Juventud) son muy limitados, y no es posible conocer cuánto presupuesto se destinó a estos espacios, ya que ni siquiera las propias autoridades conocen el dato exacto (García-García, 2017). Situación que puede explicar la marginalidad juvenil en 
términos de participación política evidenciado como la sublimación de estándares excluyentes.

De acuerdo con (Galarreta, 2016) en los comicios electorales congresales de 2016 los partidos que incluyeron más jóvenes en sus listas fueron: Progresando Perú, Democracia Directa, el Partido Político Orden y la alianza Solidaridad Nacional-UPP. Los que tuvieron menos postulantes jóvenes fueron: Perú Libertario. Conforme a lo planteado 142 jóvenes menores de 30 años postularon al Parlamento representando el (6,33\% del total de candidatos). Al mismo tiempo de este grupo, fueron elegidos solo dos, que a su vez representan el 1,54\% del total de congresistas. De ese modo, la SENAJU (2015) al contrastar el número de jóvenes electos frente al número de jóvenes postulantes da cuenta que solamente el 5,9\% de las y los candidatos jóvenes resultaron electos, frente al 15,3\% de las personas de 29 y más años. A continuación, se muestra la estadística de los candidatos electos y no electos para las elecciones regionales, provinciales y distritales en los periodos 20152018.

\section{Tabla 1}

Candidatos electos y no electos en las elecciones regionales, provinciales y distritales para el periodo 2015-2018, según categorías

\begin{tabular}{cccccc}
\hline Grupo & Electos & \% Electos & No electos & \% No electos & total \\
\hline Jóvenes & 1612 & $5.9 \%$ & 25664 & $94.1 \%$ & 27276 \\
No jóvenes & 10858 & $15.3 \%$ & 59982 & $84.7 \%$ & 70840 \\
Total & 12470 & $12.7 \%$ & 85646 & $87.3 \%$ & 98116 \\
\hline
\end{tabular}

Fuente: INFOgob-Jurado Nacional de Elecciones (2015). Elecciones Regionales y Municipales 2014

Los resultados pertinentes revelan la existencia de una gran brecha entre los que postularon y los que al final alcanzaron un escaño en las coyunturas que se suscitaron en 2015. Dejando entrever que en países democráticos como Perú, la emergencia de un ethos epocal del activismo juvenil vinculado con la "promesa de la democracia" (Blanco \& Vommaro, 2018) sigue vigente. Si bien es cierto, que en democracia, los gobiernos están obligados a rendir cuentas y a gobernar no sólo con eficiencia, sino con transparencia y atendiendo a las necesidades, demandas y aspiraciones de los ciudadano (Díaz, 2017), debido 
a que la participación electoral ha tenido una corta vida, al menos en el contexto de inscripción voluntaria y voto obligatorio (Morales \& Reveco, 2018).

La participación política en el contexto de los derechos humanos enmarcados bajo la tutela de los tratados internacionales, tales como la Convención Americana de Derechos Humanos, reconoce este derecho en su artículo $23^{\circ}$ y la Constitución Política del Perú en el inciso 17 de su artículo $2^{\circ}$ establece que: Toda persona tiene derecho a "participar de forma individual o asociada en la vida política, económica, social y cultural de la nación” (Rubio, 2013, p. 37).

Por otro lado, la acción de agruparse significa para los jóvenes, intensificar su capacidad de acción en el mundo (Cubides, 2010) lleno de sistemas dinámicos inestables o caóticos dentro de la dicotomía orden-y-caos (caosmos) (Durán, 2017). En efecto, la participación política juvenil en su vertiente debe comprenderse en relación con un conjunto de procesos políticos más amplios, aun cuando esta relación a primera vista no sea evidente. Puesto que, participar políticamente no se reduce al ejercicio del voto, sino que existen otras formas de hacerlo, como satisfacer en última instancia las necesidades e intereses (Rodríguez, 2017), entendidas como la construcción de la democralibersalización para los actores jóvenes. Por ello, cabe señalar a la región del Altiplano, donde los jóvenes reclaman la participación, no solo en función de su inserción a la política y a definirse como ciudadanos y ciudadanas, sino también, en lo que concierne al desarrollo de la personalidad (individual-colectiva) y de la cultura (Ravelo-Medina \& Radovic-Sendra, 2018, p. 399) que es la razón por la que se debe educar a las jóvenes generaciones y dirigir a la convivencia en los estándares adherentes a la paz (París, 2018).

A la luz de este complejo contexto, la presente investigación busca interpretar las representaciones sociales juveniles sobre la participación política desde la misma realidad constituido como esencia del sujeto pensante y visualizar los mecanismos de inserción a la política local, empleándose una metodología cualitativa, utilizando el grupo de discusión, entrevista en profundidad y el análisis de discurso como enfoque analítico cardinal, teniendo como partícipes a los jóvenes representantes que en algún punto se sienten desconcertados por el olvido de las autoridades en la NAM. Se concluye que, los actores jóvenes tienen razones de sobra para poder desplegar políticas públicas dentro del gobierno municipal, porque representan al grupo etario más eficiente. Señalándose en términos infinitivos que la 
lucha continúa ya que, el "poder joven” de características revolucionarias como condición intrínseca a la edad es determinante (Muñoz \& Durán, 2019).

\section{Metodología}

El diseño metodológico se ha fundamentado en la investigación cualitativa, de carácter fenomenológico-interpretativo, empleándose la técnica de entrevista en profundidad y grupo de discusión (Mora, Pujal i Llombart \& Albertín, 2017). Asimismo, utilizándose el análisis de discurso como enfoque analítico fundamental, la recuperación de las dimensiones intrínsecas permitieron identificar la retórica y el significado social integrándose la dimensión subjetiva de los investigados (Canales, 2006), asumiendo una perspectiva de análisis micro, la cual permitió pensar el proceso social objeto de estudio y las relaciones sociales de poder (Laitano, 2018), dentro de la identificación del contexto sociocultural y político en que se produjeron específicamente las representaciones juveniles (Romero, 2017).

El tratado propone construir un modelo comprensivo de los significados de la política y la democracia a partir de los discursos juveniles incluidos en la investigación (Sandoval \& Carvallo, 2017), para el análisis de discurso que se plantea buscando la interpretación crítica de los sucesos políticos enmarcados en las experiencias y las interacciones (Criado, 1992). Por consiguiente, el análisis de discurso y los grupos de discusión permitieron distintas estrategias para poder construir modalidades o matices dentro de unos tipos ciertamente generales (Revilla, 2017).

\section{Grupos participantes}

Los partícipes fueron 5 jóvenes líderes representantes de 5 organizaciones en el marco de la gobernabilidad en la ciudad Aymara. Para determinar la muestra no probabilística de tipo intencionado y orientado teóricamente (Sandoval \& Carvallo, 2017) se consideró como eje de análisis e interpretación a las siguientes organizaciones juveniles:

1. Asociación de Comunicadores Escolares del Sur Peruano (ACESP). Organización dedicada a difundir los imaginarios de los escolares en la NAM.

2. Centro de Investigación Motivacional de Alto Impacto (CIMA). Grupo juvenil dedicado a fomentar la retórica desde la subalternidad. 
3. HUAYNA WILA. Combinado indígena con la misión de difundir la cultura Aymara a nivel nacional e internacional.

4. Organización de Jóvenes Indígenas de la Ciudad de Ilave (OJICI). Colectivos juveniles indígenas avocados a la difusión del fortalecimiento de la cultura Aymara enmarcados a la participación política.

5. Asociación de Mujeres Aymaras (AMA). Grupos de mujeres jóvenes dedicados a la materialización de los derechos fundamentales de las mujeres aimaras.

Las organizaciones citadas a priori se desarrollaron en la región del altiplano, específicamente en la "Capital de la Gran Nación Aymara" (Ilave). Cabe señalar que, los grupos funcionales están dedicados a dar renombre a la representatividad juvenil y a los dispositivos culturales aimaras, tomando en cuenta la esencia y la realidad de los actores en materia de análisis y significación. Por ello, es insoslayable negar que se trabajó con 5 actores claves, quienes en su momento eran representantes de las organizaciones juveniles, con un promedio de edad que oscila entre veinte y veintitrés años (tabla 1). Ahora bien, los grupos juveniles bajo los márgenes que solicita la técnica, hicieron que se mantenga la originalidad de sus planteamientos dentro de un tiempo establecido.

\section{Procedimientos para la ejecución}

A través de un mapeo de las organizaciones juveniles más importantes se realizó la elección de los participantes esenciales. Puesto que, siguiendo la lógica de Sandoval y Carvallo (2017) el reclutamiento se llevó a cabo a través de pares simétricos que garantizaron que los participantes cumplieran el requisito de situarse, como mínimo, un año en el cargo. En el caso de esta investigación, el requisito para situarse en el cargo de dirigente juvenil fue de dos años. En tanto, los grupos de discusión dieron la apertura tomando en cuenta la realidad de los actores para de esta manera dialogar sobre la participación política y los mecanismos de inserción a la política local en la denominada NAM. También, en este punto se tiene que precisar que, las respuestas emitidas son de carácter voluntario y no son manipulados por el recolector de la información. En síntesis, los grupos de discusión se efectuaron entre agosto y diciembre de 2015, realizándose en sus respectivos distritos y teniendo la reunión final en la ciudad capital que duró un aproximado de 4 horas con previo consentimiento y firma de los asistentes en honor a la verdad. 
Tabla 2

Grupos de discusión en la investigación

\begin{tabular}{ccccc}
\hline Nombre & Edad & Sexo & Organización & Lugar de origen \\
\hline Ana (S1) & 20 & F & ACESP & Ilave \\
Eliseo (S2) & 22 & M & CIMA & Pilcuyo \\
Juan (S3) & 23 & M & HUAYNA WILA & Condoriri \\
Wilson (S4) & 22 & M & OJICI & Ilave \\
Yhosy (S5) & 21 & F & AMA & Masocruz \\
\hline
\end{tabular}

Fuente: elaboración propia.

\section{Análisis de datos}

Las entrevistas en profundidad y los grupos de discusión fueron sometidos a una rigurosa sistematización y análisis bajo un paradigma humanista y sociológico. En consecuencia, Van Dijk (1996) sostiene que el análisis supone que es posible poner "al descubierto" la ideología de los hablantes, mediante la comprensión o un análisis sistemático, siempre y cuando los usuarios 'expresen' explícita o inadvertidamente sus ideologías por medio del lenguaje u otros mecanismos de comunicación.

Ahora bien, la maniobra empleada conjeturó una transcripción literal a los grupos de discusión y con ello las entrevistas. Todos ellos analizados en 5 momentos fundamentales: En primer término, se realizó un ejercicio de paráfrasis y fichado correspondiente de los temas presentes en cada diálogo, sistematizando los planteamientos pertinentes y contextualizados al propósito de la investigación. En segundo término, se realizó un análisis transversal de las homogeneidades y heterogeneidades que se denotaron en los entrevistados y grupos de discusión. En tercer término, se precisó los imaginarios retóricos en los participantes, conocidos como representaciones sociales (Moscovici, 1961). En cuarto término, la retórica de los actores fue analizado de manera hermenéutica y fenomenológica para comprender la esencia de cada agrupación juvenil con dispositivos culturales aimaras en el plano democrático y gubernamental. Finalmente, en quinto término, se efectuó el estado de la cuestión comprendido como la teorización crítica para la divulgación al mundo académico. 


\section{Resultados}

\section{El estado de la cuestión en la juventud aymara}

El perfil antropo-ceno-político que caracteriza a los aimaras está constituido por la "sangre revolucionaria" que arde desde la marginalidad, entendido como el corpus emancipatorio que es la cualidad fundamental de los hombres que constituyen el altiplano en las paradojas del sistema político excluyente. Aquellas personas que, generación tras generación han padecido el engaño y el olvido hicieron resurgir el resentimiento hacia a un Estado que les prometió todo, pero que al final nada les dio. En ese contexto aparece la figura del general Juan Velasco Alvarado que fue protagonista de una profunda y auténtica reforma, que reivindicó en parte la situación de aquellos pueblos sumergidos en el mayor abandono. Pero, una de las mayores frustraciones se dio con la presencia en el poder de Alejandro Toledo, quien, con un rostro indígena, denominándose como el "décimo quinto Inca", prometió alcanzar ciertos logros que otros no pudieron brindar.

Por otro lado, otra de las decepciones se dio con la llegada al poder de Ollanta Humala que, con una inflexión militar decía inmolar al general Velasco, lo cual no fue así. Y una vez más, los pueblos aimaras/quechuas/originarios fueron engañados. A partir de ese momento en aquellos pueblos burlados, surge aun con más fuerza la idea de revolución como la única vía para alcanzar justicia, libertad y de ser considerados como verdaderos agentes del desarrollo en un país lleno de desigualdades. Ahora bien, la imagen que los jóvenes (ACESP, CIMA y OJICI) manejan en los grupos de discusión son realmente transcendentales e irrefutables cuando se pretende identificar el "yo" como categoría psicoanalítica que se resume en la desconfianza:

Estoy convencido que desde tiempos ancestrales los grupos de poder siempre han utilizado al Estado como una herramienta de dominio hacia los pueblos originarios y si hablamos de jóvenes, ellos nunca han sido parte de la política... Por ello, nosotros (jóvenes) nos sentimos indignados por todos esos acontecimientos que están pasando aquí y en el mundo (S2).

Se identifica con cierta notoriedad en el discurso que, existe una exasperación hacia el Estado y todas las instituciones estamentales que conviven con el poder, teniendo aquello, como consecuencia la apolítica y la desconfianza hacia los políticos. Además, entienden que 
la hegemonía del Estado/Grupos de poder (medios fácticos) son mecanismos de dominio y manipulación en todas las esferas y latitudes a las cuales éstas tienen alcance. En consecuencia, los jóvenes en su condición comprenden claramente que las instituciones no están garantizando la libertad. Por tanto, hay que destacar que la política entra en recesión y desprestigio al no contar con el tarugo democrático:

La pregunta que me planteo es: ¿Democracia? ¿de qué democracia estamos hablando? eso no existe en el país. Nuestro país está secuestrado por los medios de comunicación y las empresas transnacionales [...] yo creo que, en este punto es necesario que la nueva generación cambie la situación crítica del país y que inserte una mejor forma de entender la política [...] por ello, los jóvenes debemos encargarnos de conducir en los próximos años el destino de nuestros pueblos (S4).

Está claro que, los jóvenes al apreciar la deslegitimación de la democracia y la manipulación que ésta sufre por los medios fácticos, sienten que deben intervenir en la política entendido como la toma de decisiones y la conducción del Estado. Puesto que, la reconstrucción democrática se puede comprender como la posibilidad de recobrar un sentimiento nacionalista que los grupos juveniles han buscado desde la otredad. No obstante, con el transcurrir de los años la participación juvenil en la política ha sido frustrado y atrincherado por la "falta de experiencia" que según el grupo político de mayor edad es determinante.

Cabe señalar que, en política, el grado de confiabilidad es fundamental, de manera que, los jóvenes aun no representan esa confianza para los adultos de ser elegidos como autoridades o representantes de algunas organizaciones y movimientos políticos de renombre:

Nosotros somos la sombra del pasado, todo porque en las elecciones anteriores ciertos jóvenes tuvieron la suerte de ser electos con algunos cargos insignificantes. Pero, no realizaron una buena gestión y todo ello se pone como un mal antecedente que nos desacredita. La gente de mayor edad pide experiencia en los distintos cargos gubernamentales. Siendo este asunto un óbice para todos nosotros con aspiraciones a ser gobierno (S1). 
Algunos entienden claramente que el vocablo "experiencia" tiene distintas latitudes y contrae engranajes complejos que se traducen en la demarcación política. Por ello, todo intento de gobierno se ve opacado por un pasado desconcertante que va plasmado por la crisis de legitimidad, representatividad y participación política de los que ya fueron elegidos:

Debemos crear nuestros propios mecanismos de gestión pública y jamás esperar que otros nos impongan los lineamientos que vienen de arriba (poder)... Por ende, está claro que una de las tantas vías para recobrar la confianza es reconfigurar nuestras instituciones democráticas que están hundidos en la corrupción. Asimismo, debemos generar referentes jóvenes con la capacidad de asumir responsabilidades políticas y jurídicas construyendo un modelo de ciudadano ético-político... (S4).

Los estigmas perfilados categóricamente por los jóvenes, manifiestan que es necesario y primordial la reestructuración del aparato público en los estándares que la Constitución (1993) emana. En efecto, la ética/biopolítica entendido en los sujetos como el discernimiento de lo bueno y lo malo que ostenta el poder, no se ha comprendido en las esferas institucionales adherentes a la población joven. Por ello, se apuesta por los "referentes" o líderes que puedan mejorar las dimensiones de los imaginarios que, deben ser tomados en cuenta como itinerarios adoptivos en contextos culturalmente situados que visibilicen tendencias populares ya que, de estas, pueden devenir ideologías que se conceptúan como representaciones culturales (Grau, 2017).

Sin duda, se analizan los discursos y los imaginarios que se desprenden de las autorepresentaciones que hacen los propios jóvenes (Soto \& Visa, 2017). Sin embargo, lo descrito no se puede analizar al margen de la hegemonía, sintetizado como poder; que se define como la capacidad que tiene una persona o grupo para imponer, por diferentes medios, la propia voluntad; la dominación, como la probabilidad de encontrar obediencia (Abril, 2018). Además, el poder y la dominación en palabras de Hobbes y Weber se pueden conceptuar como dos caras de la misma moneda. Ya que, los efectos indirectos presentados en los usos políticos (Zumárraga, Reyes \& Carofilis, 2017) generan acuerdos para asignar privilegios bajo una concepción personalista (Osorio, 2018), egoísta y sectarista que lleva a la política a una hecatombe evidente. En definitiva, la creciente desconfianza y deterioro del sistema de poderes acabaron sepultando la esperanza y la fe de la población cuando se refiere a la 
ataraxia institucional. En pocas palabras, la idea inicial del emporio está enmarcado en la siguiente sentencia: si el Estado (sus gobernantes) no cumple con sus derechos concedidos, tales gobiernos pierden legitimidad para imponer obligaciones jurídicas (Bertomeu, 2017).

\section{El discurso político de los jóvenes aimaras en una era de falacia óntica}

Lo político se conceptúa como la aglomeración de experiencias de la política convencional relacionado con lo óntico en palabras de Chantal Mouffe. Ahora bien, la ontología de los jóvenes ha sido reducida a términos epistemológicos muy simples en el sistema occidental en el cual domina la falacia ataviado de veracidad que se oculta detrás de la casta política corroído de las falsas soluciones ofrecidas a los actores jóvenes. Dicho de otra manera, la NAM ha sido el atrio de los actores (ACESP, CIMA y HUAYNA WILA) desconcertados y utilizados en cada proceso coyuntural:

Me siento molesto, decepcionado y cansado de los políticos de siempre. Ya que, [...] en política, solo nos utilizan para hacer pintas y banderas... si queremos mejorar el destino de nuestra gente para llevar al desarrollo económico, cultural y político, nuestra forma de pensar debe cambiar. Pero, no vasta con decir que vamos a cambiar. Aquí faltan acciones concretas para sentir el verdadero cambio... hemos malentendido la política. Hoy por hoy, hacer política es encontrar un mecanismo de asalto a las arcas del Estado. Todo el mundo quiere sacar provecho de la política, pero nadie ve a la política como un servicio a la sociedad (S2).

Es evidente la existencia de un modelo político binario que se acentúa a plenitud en la expoliación-colonial deducido como: legitimidad/rechazo, experiencia/razón, adulto/joven, discurso/ejecutor, teoría/práctica, doxa/episteme, tradicional/tecnócrata, el que solo habla/el que solo hace pintas y banderas. Siendo la notoriedad de la dicotomía simplista el que prevalece cuando de política se habla en la región aymara. Bajo ese enfoque, se fundamenta la propuesta de transdisciplinariedad y transculturalización política en el sentido de la inclusión-acompañamiento-acercamiento del "otro" en los actores políticos adultos/jóvenes. Por tanto, la manifestación como punto de partida del análisis hermenéutico, muestra claramente que los jóvenes son utilizados como herramientas-dispositivos-apéndicesengranajes en cada coyuntura electoral. A partir de esa compleja realidad, los denominados 
dispositivos políticos entienden que están ante la evidente crisis democrática-política, produciéndose una serie de resentimientos-críticas hacia los agentes que entienden y quieren solo retrocesos políticos como añoranza de un pasado colonial en el cual se podía desfalcar a los que menos tienen:

Nuestro país lamentablemente aún tiene un pensamiento colonial que viene de afuera (Europa), sus habitantes están absorbidos por ideas de poder y dominación [...] en ese sentido, puedo afirmar que ya nadie busca la cohesión social entendido como la ayuda mutua... en la política actual la situación es peor. Hoy se manejan jerarquías que ponen a uno sobre otro... Por tanto, yo me pregunto, cuál es la necesidad de hacer aquello... Hasta cuando vas a una iglesia el sacerdote dice: yo soy el padre, el supremo, soy la voz del señor; en la universidad pasa lo mismo, debido a que a nuestros profesores les decimos: doctor, Ingeniero o licenciado buenas tardes. Porque no simplemente llamarlo Eliseo como estás, buenas tardes, si somos iguales. El trato debe ser de humano a humano. Pero no es así, ya que en nuestra mente está insertada la colonialidad que prácticamente ha opacado el pensamiento originario (S1).

Por otro lado, existe una naturalización del colonialismo/patriarcal/capitalista/ egocentrista/sexista/racista en todos los pueblos de corte originario debido a la imposiciónobligada que los mismos sufrieron a plena vena abierta. Por ello, en el contexto vigente los jóvenes sienten la expresión insoslayable de la presencia de un colonialismo político que ha impuesto barreras, patrones y cánones culturales-económicos-políticos para desterrar el doxa gnoseológico/epistemológico/ontológico de los aimaras. No obstante, los líderes y sus respectivas organizaciones están en la búsqueda incesante del nuevo paradigma enfocado bajo los estándares del principio de la filosofía sentipensante apegado a la praxis dialéctica del Suma Qamaña (Buen Vivir):

Quiero remarcar como punto esencial... que, en esta parte de nuestra historia, falta recuperar la convergencia entre hombre, política y naturaleza [...] Por tanto, si hacemos las actividadades políticas bajo estas tres dimensiones existirá un punto de equilibrio que nos conducirá a una democracia real, representativa y participativa. Bajo esa perspectiva, este pueblo (NAM) podrá encontrar esa anciada democracia con el pensamiento autónomo... Los aimaras hemos tolerado durante mucho tiempo la política tradicional 
excluyente hacia las organizaciones juveniles indígenas... Ahora bien, como jóvenes debemos construir y luchar por políticas públicas enmarcados bajo el cliché del amor a nuestra Pachamama, dejando de lado la explotación, odio y falsedades que se han impuesto en las políticas manipulatorias que usan los políticos en la actualidad (S3).

Está claro que, la sabiduría/filosófica/ontológica milenaria tiene su origen en la fundamentación crítica que se antepone a los paradigmas occidentales que reencarnan en la juventud de sangre Lupaca-Puquina-Colla el símbolo espectral de resistencia y reivindicación. De tal forma que, se crea una filosofía desde el Sur, con un logos emancipador que quiebra los límites hegemónicos del "capitalismo invencible" y del "colonialismo sin desenlace", ya que, la presencia de los pueblos milenarios que han logrado la recreación de su hábitat a través de una relación simbiótica directa (Castro-Gómez, 2007; De Sousa, 2011), entre hombre-naturaleza-política, bajo el derrotero de la filosofía sentipensante que significa, amar a la Pachamama (Madre Tierra), es considerado como la máxima expresión del panlogismo ancestral Aimara, construyendo una nueva forma de comprensión metafísica de la política local. Por tanto, las epistemologías del Sur, son un conjunto de posturas ideológicas, que han venido siendo desarrolladas en Sudamérica desde la década de los 80 y tienen como finalidad la emancipación del pensamiento-cultura-investigación, contraponiéndose a la hybris que es el gran pecado de Occidente al cual se le ha llamado también el giro descolonizador-despatriarcalizador (Castro-Gómez, 2007; VillavicencioCaparó \& Alvear-Córdova, 2017; Pérez, 2018).

\section{Mecanismos de inserción a la política local aymara}

La tragedia de la civilización post contemporánea para Jacques Maritain no proviene de haber cultivado y amado la ciencia en alto grado y obtenido triunfos admirables; la tragedia proviene de que esta civilización ha amado la ciencia contra la sabiduría; y no escapará a la muerte, sino aprendiendo a reconciliarlas, para lo cual se requerirá mucha inteligencia y amor. Por otro lado, las pretensiones de disminuir los dogmas de la ciencia experimental, han llevado profundamente al dominio del positivismo satánico/teologal en el sistema-mundo visto desde la alteridad-otro-periferia. En ese sentido, deben implantarse tres dispositivos elementales para construir el mejor de los mundos posibles y sub mundos posibles contemplados en: filosofía política/perfil político/tecnicidad sostenible. Todos ellos, servirán 
para dar el funcionamiento fáctico-positivo-prospectivo a los jóvenes (OJICI y AMA) en latencia política.

Por tanto, se parte de la sui géneris de la conjunción filosofía-política que debe primar en los jóvenes al momento de hacer política. Cabe señalar, que, en este punto, la filosofía juega un rol fundamental porque contribuye a dar forma a la estructura política a través de la teoría y la acción tal como Mario Bunge sugiere en los siguientes flujos: filosofía-teoría políticadebate político-decisión política-planificación-ejecución-evaluación-rediseño de la política o plan. Y es, en ese espacio que, hasta los materialistas ingenuos podrían objetar que se trata de una concepción idealista, no tomando en cuenta que las deliberaciones cognitivas encontradas en el inconsciente son los que verdaderamente determinan la teoría y la acción política en los parámetros juveniles:

En política, nos faltan ideas, propuestas y dar alternativas de solución a los problemas que presenta esta nación... puedo decir con mucha tristeza que a todos los jóvenes que decidimos insertarnos a la política, nos falta filosofía, nos falta pensar y ver más allá de lo que la gente normal ve... más que ver, nos falta la observación y el análisis crítico para poner en aprietos a los políticos que han gobernado siempre [...] Sin embargo, con el tiempo, nuestra capacidad intelectual en el campo político se ha vuelto diferente y puedo presumir que ha mejorado de manera abismal, todo esto, gracias a los debates y conferencias que se fueron realizando en las organizaciones en las cuales militamos y somos representantes... Ahora, el objetivo inmediato que tenemos es: romper el prejuicio de que los jóvenes somos un fracaso haciendo política (S5).

Los actores jóvenes reconocen que existe la precariedad del pensamiento situado, traducido como la carencia de la filosofía crítica-contestataria-revolucionaria frente a la filosofía eurocentrista (griega). Pero, más que un enfrentamiento simplista, los partícipes buscan la vinculación de la superestructura andina con la occidental eso que más arriba se ha denominado como filosofía transcultural-transdisciplinario. Así mismo, los actores juveniles están más que dispuestos para demostrar que no son un fiasco-fracaso-decepción en política, sino, todo lo contrario. Ellos tienen el potencial, la inteligencia, la voluntad y la energía suficiente para transformar, mejorar y reivindicar el destino de la NAM. Por otro lado, la política actual debe facultar el poder a las juventudes a través de mecanismos democráticos 
participativos que aseguren su representatividad, así como un ejercicio efectivo de su ciudadanía de manera integral, teniendo en cuenta el perfil del político joven:

El Perú presenta una crisis histórica de representatividad y gobernabilidad, en especial la NAM... me atrevo a decir que, faltan políticos que inmolen a un modelo o prototipo de ciudadano. De esta manera, planteo la siguiente pregunta: ¿cuál es el perfil del político eficiente destinado a conducir nuestra nación?... la respuesta a esta interpelación está constituida en tres características elementales: primero, debe ser ético; segundo, debe poseer sostenibilidad en el tiempo y tercero, tiene que tener tecnicismo político [...] (S4). Es incuestionable la crisis de representación en todas las esferas políticas del Estado. Además, se muestra claramente que, en la acción política juega un rol determinante los estigmas-ideologías-procesos afectivos dando entrever la magnitud y la complejidad de la participación política. Las categorías que se utilizan ponen en tela de juicio a lo que debe y no debe poseer el actor político joven para constituir su legitimidad en el sentido amplio de la Ciencia Política. Haciendo el análisis factorial, el primer punto hace referencia al cómo debe ser el político joven una vez que se sitúa en el poder. Ya que, su objetivo inmediato es realizar un gobierno transparente y eficiente, dejando de lado la política basada en la apariencia, doble moral, chantaje y manipulación mediática, llevando al ocaso a la nación Altiplánica.

El segundo punto hace alusión a la temporalidad del gobierno, teniendo en cuenta el código identitario-consuetudinario-milenario expresado en el idioma aymara, que es el medio para la sensibilización correspondiente en un marco democrático. Asimismo, se busca la formación de cuadros políticos con identidad-tradición-consciencia de clase para que puedan ser capases de garantizar la cultura ambiental-sostenible-sustentable en una era de caosmos climático. Por último, el tercer punto está referido al qué debe poseer el gobierno local presidido por el político joven:

No se puede asediar a los jóvenes con la vieja retórica de que a ellos les falta experiencia y la edad suficiente para asumir cargos políticos... Sin embargo, es necesario manifestar que, los que van a realizar política local mínimamente deben haber militado en los movimientos sindicales-estudiantiles que se generan y gestaron en las diferentes universidades o movimientos sociales como es el caso del aymaraso [...]. Asimismo, 
debo ser claro en esto, los políticos jóvenes deben ser los mejores estudiantes (tercio y quinto superior) si están en los estamentos superiores universitarios, en cambio, los que no tuvieron la oportunidad de acceder a un centro superior, deben contar con un alto grado de altruismo, liderazgo y ética para la constitución integral del pueblo, ya que, de lo contrario estaríamos cayendo en la política tradicional impregnado de irrelevancias (S4).

La disyuntiva entre los sujetos de mayor edad con experiencia establecida y los sujetos de menor edad (jóvenes) que carecen de experiencia, ha sido y seguirá siendo uno de los debates inacabables en todo el Perú y más aún en la NAM, llevando al egoísmo-apatía-irrealismo político a los jóvenes con ansias de participar activamente en la política local. Se puede afirmar también, que existe una sobre valoración exagerada a los años en política, lo cual, desde el análisis que se hace a los dirigentes juveniles es negativo. Avanzando con este razonamiento, aparece la militancia política y revolucionaria marcada por las posibilidades de autonomía, como requisito indispensable para recuperar la fe pública en las instituciones estatales, teniendo en cuenta el conocimiento crítico de las ciencias sociales y el papel transformador de los jóvenes como factores exógenos o contextuales (Cruz \& Fuentes, 2017; Herrera, 2017; Delgado-Fernández \& Cazorla-Martín, 2017; Lores \& Jociles, 2018; Lorenzano, 2018).

Consideremos ahora, que los movimientos sociales que tuvieron afloramientos en la región altiplánica como estatismo del resguardo ancestral-milenario denominado como aymarazo (2011) tienen, ideologías y ecuaciones inkarristas-emancipatorios frente al desdoblamiento occidentalocéntrico perjudicial para los aymara-hablantes. Además, se debe comprender las motivaciones que llevaron a los dirigentes políticos como Walter Aduviri Calizaya a querer restaurar autopoyéticamente una nación burlada-soterrada-fulminadaolvidada por los gobiernos de turno. Con respecto al dirigente en mención, que para el periodo de gobierno 2019-2022, resulta ser electo como gobernador regional de Puno, éste tendrá que enfrentar múltiples retos para la consecución real de toda la NAM. No obstante, a partir de lo examinado se crean convergencias y divergencias. Siendo el líder aymara para muchos, el símbolo de la ideología tupakatarista que representa la reivindicación póstuma en el final de los tiempos (Korstanje, 2009; Huanca-Arohuanca, 2019; 2020a; 2020b; 2020c; 2021; Huanca-Arohuanca \& Núñez, 2020; Huanca-Arohuanca \& Geldrech, 2020; Huanca- 
Arohuanca et al., 2020; Huanca-Arohuanca, et al., 2020; Huanca-Arohuanca \& Pilco, 2021a; 2021b).

Mientras que, para pocos, es catalogado como un simple caudillo-intransigente que se sirvió y utilizó a los indigentes. Pero al final, lo más importante es que Aduviri tiene demasiada legitimidad y podemos incluso presumir que los pueblos han encontrado en él un emblema de esperanza y resistencia, así como los bolivianos en Evo Morales. Pero, en las regiones convulsionadas bajo la transformación de las "zonas de contacto" y espacios dialógicos intersubjetivos (Errejón, Espasandín \& Iglesias, 2007) que ponen en el centro a los jóvenes aimaras, la cooperación anti-sistémica se efectúa bajo los peyorativosdiscriminatorios de parte del occidente hacia los indígenas en una grave y profunda crisis civilizatoria vinculada a la quiebra de ese mito del "progreso" (Gonzalorena, 2017; Polo \& Piñeiro, 2019). Ya que, el sistema-mundo monocultural crea paradojas como: egoísmo/altruismo, prudencia/moralidad en los aspectos más pasionales y visuales de atracción analizados en el eros político local desarrollados en las exhibiciones simétricasasimétricas entre jóvenes y adultos (Samamé, 2017; Rodríguez-Santero, García-Carpintero \& Porcel, 2017; Black, 2017; García-Granero, 2017).

\section{Discusión}

Es fundamental mostrar los puntos de quiebre o fallas históricas en lo referente a la participación política juvenil en la NAM. Sabiendo la complejidad de la disyuntiva caósmica existente entre la experiencia y la iniciación política, los errores de no incluir fluidamente a los actores juveniles merman la construcción de una agenda pública, en razón de los factores determinantes y permeantes para la formulación de políticas públicas y un adecuado manejo de los diferentes sistemas de información que conllevan a la transparencia en términos de fortaleza, la toma de decisiones y el control de la función administrativa (Vargas, Leal \& Hernández, 2018). Además, teniendo conocimiento de la indolencia, la falta de sensibilidad, la apatía política, los temores, la falta de apoyo institucional y la manipulación política, hacen la imposibilidad de oportunidades y escaso compromiso de ayudar a otros jóvenes que vienen de la acción colectiva (Castañeda, Narváez \& Calvache, 2017; Aguilar-Forero, 2017; Rincón, 2018).

Lo anterior muestra una de las grandes incongruencias que se presenta en el proceso 
participativo juvenil. Sin embargo, ante el desenfrenado avance de la globalización y la situación cataclísmica de desvanecer una serie de elementos identitarios, se ha perfilado la intervención de un enfoque político-intercultural en las agendas nacionales y locales, para enmendar los problemas paralelos que se suscitan al son de la incertidumbre política y lleno cambios. Puesto que "sería ingenuo pensar que la política simplemente seguirá como hasta ahora" (Sintomer, 2017, p. 41).

El estudio bordea las organizaciones y sus respectivos representantes juveniles bajo la deslegitimación-debilidad-inestabilidad del poder frente a las grandes corporaciones internacionales que toman el control del Estado, teniendo efectos negativos y significativos. Por consiguiente, aparece el antagonismo de participación/apatía, fulminando el proceso democrático normal de la participación política. Además, la política se ve lesionada cuando no hay una vinculación entre lo que se quiere para la población y lo que desea la población, peor aún, cuando de por medio no se visualizan cambios trascendentales. Paralelamente, hay que hacer notar, los diferentes prototipos que interactúan en la construcción de una democracia diferente que integra masivamente a los jóvenes (varones y mujeres), ya que, el estudio está centrado en la viabilidad y alcance correspondiente, para que se logre una significante labor representacional, tal como se eyecta en el siguiente gráfico 2. 
Gráfico 2

Ecuación política tridimensional en los jóvenes de la NAM

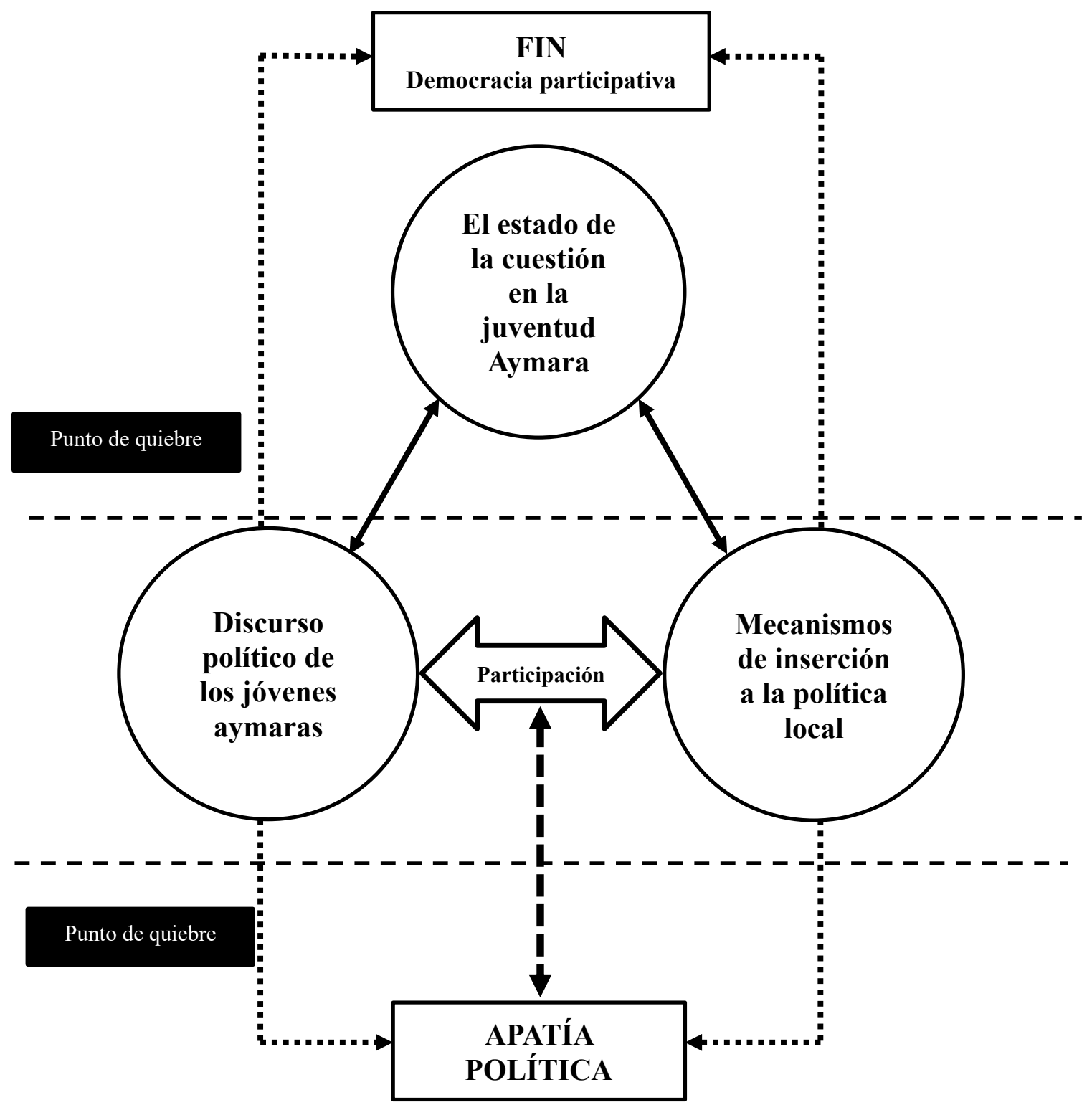

Fuente: elaboración propia.

A través del esquema concebido, el estudio se dirige para comprender sinérgicamente las RS de los jóvenes de la NAM y determinar la búsqueda de la democracia participativa en todas las organizaciones partícipes de las democracias emergentes, debido a que, su renacimiento obedece al contexto político, histórico (García, 2018) y filosófico, hacia la 
cooperación con el empoderamiento político de los ciudadanos para abrir las puertas a un modelo de democracia directa (Guzman, 2017; Font, 2018) e incluyente en todas las dimensiones coyunturales de gobernabilidad. Tales planteamientos convocan a entender el estado de la cuestión en un marco de la participación política juvenil que no ha sido insertado como se presuponía en los gobiernos locales.

A partir del análisis tangencial, el discurso político de los jóvenes aimaras y los mecanismos de inserción política están comprometidos para lograr el fin entendido como democracia participativa, pero, siempre en cuando que garanticen como plantea Hernández \& Gimate-Welsh (2018) el sistema electoral y el sistema de partidos que vienen a ser los elementos esenciales en las democracias modernas, constituidos por el voto directo de los ciudadanos de a pie. Además, en ese trance, principia la interrogante ¿Qué es la democracia participativa? Esta pregunta no tiene una respuesta sencilla, ya que, ni siquiera en la literatura especializada existe consenso respecto a su significado. Por tal razón, la democracia tiende a considerarse como un concepto polisémico y controvertido (Alvarado-Espina, 2018).

No obstante, desde la óptica propia, la democracia participativa se debe vislumbrar como el Estado que integra-vincula-entiende-atiende a sus conciudadanos sin objeción alguna, un Estado Plurinacional en una "democracia en transición" (Driscoll, 2017) que comprenda y respete las diferencias entre sus habitantes. Por tanto, en un Estado de tal magnitud debe reanudarse el debate y el deseo crítico para desplegar una democracia con libertad. Además, se debe garantizar la evaluación constante por los ciudadanos al sistema político, puesto que, la expectativa que tienen los pueblos es, de vivir en un régimen que garantice derechos y libertades democráticos (Nunes \& Ranulfo, 2017; Monsiváis-Carrillo, 2018).

Los actores emergentes comprenden categóricamente la importancia del discurso político para generar espacios de diálogo y debate. Siendo éste, el aspecto más connotativo para la construcción de la democracia participativa como fin. Además, Ortiz (2018) señala que el discurso político ha ido construyendo su significado en un proceso en el que la posición respecto al poder y la ideología operan como «reductores» del determinismo político. Así mismo, para Angelcos, Jordana y Sandoval (2019) surge el discurso político radical, que promueve una transformación profunda de la sociedad en múltiples ámbitos.

En primer lugar, surge la idea de derribar el modelo neoliberal y capitalista. En segundo lugar, surge la idea de generar una política en la que "el pueblo mande", es decir, donde el 
poder le sea arrebatado a los ricos/poderosos/clase política tradicional, para que finalmente el poder sea devuelto al pueblo. Sin embargo, en la NAM surge la manipulación psicológica de los estigmas (Trujillo, et al., 2018; Batista \& Codo, 2018; Agudelo-Vélez, 2018) juveniles debido a la "opacidad" que éstos sufren por la casta política tradicional constituido como una especie de ocultamiento o manipulación común a todos (Santos, 2018). Por tanto, la manipulación política no es reciente, ya que, desde el surgimiento de la polis se usó como instrumento de sujeción desde las esferas de poder hacia las esferas carentes de hegemonía.

En ese sentido, en la NAM los jóvenes vienen siendo opacados con la vieja retórica de que ha éstos les falta práctica, pues bien, el espacio de lo discursivo se superpone al campo de las relaciones sociales y que éstas son tales porque tienen y producen sentido (Biglieri, 2017) dentro del paradigma colonial/patriarcal/monocultural. Pues bien, en democracia participativa el joven político no solo debe gravitar como dispositivo o una herramienta facultando la victoria del candidato con experiencia, sino que, debe ser el conductor de la masa popular en la búsqueda de un país-pueblo proyectado a la integración de hombre/naturaleza/política.

Por su parte, los actores que profieren los mecanismos de inserción política, se enfrentan con el desafío de redefinir los sub mundos emergentes contemplados en tres categorías fundamentales, tales como: filosofía política, perfil político y la tecnicidad sostenible bajo el prisma del devenir social. Por tanto, con el primer punto se puede comprender a la filosofía política como la búsqueda del fundamento último de poder, que permite responder la interrogante “¿a quién debo obedecer?” y “¿por qué?” obteniendo como respuesta, la justificación última del poder y la legitimidad del poder para finalmente hallar una óptima república (Bobbio, 2005). Claro que, eso para la NAM se cataloga como la democracia institucional legítimamente aceptado en todos los ángulos de gobierno. El segundo y el tercer punto, están eyectados a la obtención del perfil político y el tecnicismo político basado en la trilogía ética-sostenibilidad-tecnicismo. Por consiguiente, para Dudley (2018) todos los seres humanos luchan por su bien, y la ética nos da las reglas para alcanzar el bien y paralelamente alcanzar la felicidad.

Ahora, con referente a la sostenibilidad/sustentabilidad se han manejado en demasía los términos como: la sostenibilidad económica, la sostenibilidad social y la sostenibilidad ambiental. Pero, falta la sostenibilidad política que puede ser entendida como el hecho de 
garantizar una mejor calidad de políticos limpios, con una mente racional prospectivo que pueda coexistir con la naturaleza y en la cual la ciudadanía participe de las decisiones políticas desde la óptica de la integralidad de las dimensiones económicas, sociales, ambientales y de los valores, que conlleven a una revolución global (Zarta, 2018).

Por último, el nuevo panorama global y local requiere identificar, diseñar, desarrollar nuevas políticas y estrategias para combatir la apatía política. Por ello, es necesario que se reconozca la complejidad y el mayor grado de tecnicismo que requieren las políticas públicas (Barboza, 2013; Chirinos, 2017) y se instrumentalicen las medidas para fortalecer a los gobiernos locales con proyección a los espacios nacionales, sin caer en el antagonismo de ser revolucionario/oportunista (Rubio, 2019).

Bajo ese cliché parametral, Los actores comprenden que el estado de la cuestión está referido al momento-contexto-espacio-tiempo por el cual franquean los jóvenes aimaras en la búsqueda de la hegemonía y el protagonismo político dentro de un estadio de gobernabilidad que se dirige hacia dentro, a través, del sistema de partidos políticos que siguen siendo instrumentos indispensables de la democracia de masas (Garrido, 2017). Pero, si estos engranajes no funcionan adecuadamente, los canales democráticos se deslegitiman a tal punto que la percepción que los jóvenes tienen sobre la política se redirecciona a un desencanto o desinterés de la praxis política, percibida como la desafección, que es un concepto que se ha venido utilizando con frecuencia en el debate público, como sinónimo de apatía política, descontento o desconfianza (Ramos-Galarza, Apolo-Buenaño \& JadánGuerrero, 2018; Lorente \& Sánchez-Vítores, 2018).

De tal modo, parece ser que en la NAM se ha producido la distopía democrática, es más, parece existir un divorcio entre la clásica relación carisma política-democracia. En otras palabras, el surgimiento del rechazo a la democracia a nivel poblacional y la falta de confianza en las instituciones de la democracia pueden provocar que los ciudadanos "apuesten" por un retorno hacia un régimen autoritario. No obstante, el desmantelamiento de lo ataráxico en política, en principio, no tiene por qué conllevar al colapso de la democracia, ni su ausencia o debilidad ser justificación para la adjetivación de la democracia como algo disminuido en calidad, sino que, debe otorgar la lucha por la esperanza hacia una democracia participativa integradora de los jóvenes, es más, la política debe entenderse como la búsqueda del sentido de la coexistencia (Serrafero, 2018; Bohigues, 2018; López, 2018; Radic, 2018; 
Gómez, 2018; Barrios-Suvelza, 2018).

\section{Conclusión}

Es habitual que en la actual coyuntura no se considere como parte de las decisiones políticas a los entes juveniles, porque, a través del historial antagónico de la NAM, el modelo político tradicional se ha venido imponiéndose sistemáticamente a la nueva forma de replantear la política en función del rol protagónico de la participación política juvenil. Por consiguiente, se puede afirmar que los nuevos sujetos en política solamente son meros dispositivos del sistema hegemónico tradicional, lo que implica, la anulación contractual de la generación joven en los espacios de democracia participativa. Ya que, lo anterior conduce a una deslegitimación de la política que al final se resume en apatía política que lesiona todos los canales democráticos desarrollados en las multidiversas teorías políticas del poder. Ahora bien, el discurso político de los jóvenes aimaras rechaza el modelo político binario, apostando por una propuesta de transdisciplinariedad y transculturalización política en el sentido de la inclusión-acompañamiento-acercamiento del "otro", en los actores políticos adultos/jóvenes; los mecanismos de inserción a la política local plantean tres dispositivos elementales para construir el mejor de los mundos posibles y sub mundos posibles contemplados en: filosofía política/perfil político/tecnicidad sostenible, siendo determinantes para la concertación; el estado de la cuestión en la juventud Aimara está referido al momentocontexto-espacio-tiempo por el cual franquean los jóvenes aimaras en la búsqueda de la hegemonía y el protagonismo político. En definitiva, las tres dimensiones abordadas en el proceso de la integración multifacética, basado en los fundamentos políticos que emanan desde la interpretación hermeneútica, conducen al cumplimiento ecuánime del estado de la cuestión juvenil para alcanzar el fin sintetizado como la adquisición del poder en las esferas del gobierno de parte de los "otros".

En un plano estructural, la institucionalidad política debe ser replanteado en aras de lograr políticos realistas-conscientes-situados bajo el supuesto de la filosofía Aimara en proceso de construcción y consolidación, puesto que, el abordaje dinámico-procesual muestra que, los jóvenes al apreciar la deslegitimación de la democracia y la manipulación que ésta sufre por los medios fácticos, consideran que deben intervenir en la política entendido como la toma de decisiones y la conducción del Estado dentro del funcionamiento real de la NAM. También surge, la necesidad de replantear el discurso retrógrado manejado por los que excluyen a los sujetos jóvenes, insertando un enunciado capaz de pensar los sistemas de poder como una serie de dispositivos heterárquicos vinculados al funcionamiento real de la cosa pública. En consecuencia, en el sistema político que pretenden constituir los actores jóvenes de la ciudad Aimara no pueden existir estructuras ininteligibles que estén fuera del foco, sino que, todos los niveles de gobierno deben ejercer algún grado de influencia sobre los aspectos particulares y/o colectivos para atender las coyunturas de carácter político-histórico que posibilite la consolidación del pensamiento diacrónico del Suma Qamaña (Buen Vivir) intrínsecamente vinculado a la filosofía sentipensante, para finalmente lograr la ruptura 
ontológico-gnoseológico-epistemológico del hombre Aimara con el hombre occidental.

El presente se desdobla bajo el análisis de los grupos juveniles relacionados a las organizaciones políticas subalternas, excluidos, omitidos, silenciados e ignorados por aquellos gobernantes de turno. Los líderes de aquellos grupos de discusión resultan ser limitados a la hora de hacer una buena interpretación fenomenológica. Sin embargo, a partir de ahí, es posible realizar generalizaciones que ayuden en la construcción del modelo democrático real-eficiente, para la enarbolación de la gente que constituye la NAM y que desarrolla un altruismo popular con la ética como contenido contextual. Cabe señalar, que, en los últimos cinco años la nación objeto de análisis ha sufrido una dialéctica fundamental en su paradigma cultural grávido de contingencias, en el cual es innegable el grado de influencia del sector juvenil con respecto al gobierno local. Muestra de lo preliminar, es que, surgen los movimientos sociales como el Aimarazo y otras formas de reivindicación suscitados desde el altiplano para con el Perú. Por ende, lo anterior permitirá el inicio del debate y la resignificación de la política local para la búsqueda de gobiernos capaces de plantear el viraje ontopolíticodecolonial/despatriarcalizador.

La ecuación política tridimensional en los jóvenes de la NAM, en cierta medida, puede definir el horizonte que se busca, a través de las experiencias de diálogo desarrollados con los grupos dirigenciales en los espacios juveniles carentes de democracia participativa. Además, los promotores de las reformas políticas en la nación altiplánica, son jóvenes, que utilizan métodos de debate para poner en tela de juicio el funcionamiento del aparato público para su real y óptimo funcionamiento. También se puede sintetizar, que los aimaras no se habían percatado de la inserción del ego conquiro, que venía acompañado de la episteme eurocentrista/patriarcal/sexista/racista, ya que, éste, pretendía fulminar el conocimiento doxa y anular la resistencia ontológico de los sujetos aimaras denominados como damné, frente a los ojos del grupo dominante. Pero, a pesar de eso, persisten las ideologías y ecuaciones inkarristas-emancipatorios para vivir en un país-pueblo que garantice derechos y libertades fundamentales inherentes al ser antropológico. En conclusión, los actores jóvenes tienen razones de sobra para desarrollar políticas públicas dentro del gobierno municipal, porque representan al grupo etario más prospectivo-eficaz en el manejo de las políticas públicas que al final posibilitarán la construcción trascendental ideológica-política-filosófica-social de la integración y transformación sistémico-complejo del sujeto joven. En definitiva, se puede señalar con alegoría la siguiente premisa: aquel día que los jóvenes sepan que su onticidad esencial es hacer la revolución, el sistema-mundo no será este, sino, otro, al cual llamaremos Mundiverso.

\section{Referencias}

Abril, F. (2018). Rethinking Domination. Axel Honneth and the Legacy of Critical Theory. Revista Mexicana de Ciencias Políticas y Sociales, 63 (232), 103-128. https://doi.org/10.22201/fcpys.2448492xe.2018.232.58154 
Acosta-Silva, D. (2017). Tras las competencias de los nativos digitales: avances de una metasíntesis. Revista Latinoamericana de Ciencias Sociales, Niñez y Juventud, 15 (1), 471-489. https://doi.org/10.11600/1692715x.1513014062016

Agudelo-Vélez, D. M. (2018). Presentación. Impacto del conflicto y la violencia sobre la salud mental: del diagnóstico a la intervención. Revista de Estudios Sociales, 66, 28. https://doi.org/10.7440/res66.2018.01

Aguilar-Forero, N. (2017). Jóvenes, memorias y comunidades emocionales: la experiencia de H.I.J.O.S. y de Contagio en Bogotá, Colombia. Rev. Estud. Soc, 62, 42-53. https://doi.org/10.7440/res62.2017.05

Alvarado-Espina, E. (2018). Una aproximación crítico-contextual al declive de la democracia en la era neoliberal. Revista Española de Ciencia Política, 47, 69-91. https://doi.org/10.21308/recp.47.03

Angelcos, N., Jordana, C., \& Sandoval, C. (2019). Sólo en el pueblo confiamos: la estructura moral del discurso político radical de los pobladores en el Partido Igualdad. Izquierdas, 46, 22-46.

Arias-Cardona, A. M., \& Alvarado, S. V. (2015). Youth and Politics: from formal participation to informal mobilization. Revista Latinoamericana de Ciencias $\begin{array}{llllll}\text { Sociales, } & \text { Niñez } & y & \text { Juventud, } & 13 & \text { (2), }\end{array}$ https://doi.org/10.11600/1692715x.1322241014

Arias, D. B. (2015). Presupuesto Público dirigido a Niñas, Niños y Adolescentes Perú 2014.

Barboza, Ó. (2013). Clentamiento global: "La máxima expresión de la civilización Petrofósil." Revista Del CESLA, 16, 35-68.

Barrios-Suvelza, F. (2018). Countermajoritarian control as framework for the analysis of the influence of the new Latin American constitutionalism upon democracy. Revista Española de Ciencia Política, 47, 39-68. https://doi.org/10.21308/recp.47.02

Batista, A. S., \& Codo, W. (2018). Dirty Work and Stigma: Caretakers of Death in Cemeteries. Revista de Estudios Sociales, 63, 72-83. https://doi.org/10.7440/res63.2018.06

Bertomeu, M. J. (2017). Poverty and Property: Two Sides of the Same Coin? A Kantian Republican Approach. ISEGORÍA. Revista de Filosofía Moral y Politica, 57, 477- 
504. https://doi.org/10.3989/isegoria.2017.057.04

Biglieri, P. (2017). Populismo y emancipaciones. La política radical hoy. Una aproximación (con variaciones) al pensamiento de Ernesto Laclau. Revista Mexicana de Ciencias Politicas y Sociales, 62 (229), 245-262.

Black, C. F. (2017). Modern cannibalism: The trade in human body parts. Tabula Rasa, 26, 29-50. https://doi.org/10.25058/20112742.187

Blanco, R., \& Vommaro, P. (2018). Activismo juvenil en los años ochenta en Argentina: dos generaciones políticas entre el partido y la universidad. Revista Latinoamericana de Ciencias Sociales, Niñez y Juventud, $16 \quad$ (2), 839-852. https://doi.org/10.11600/1692715x.16213

Bobbio, N. (2005). Teoría General de la Política. Madrid: Editorial Trotta.

Bohigues, A. (2018). The Support for Democracy in Latin America's Parliaments: An Analysis of the Ambivalent Democrat. 2016, 51-82.

Cajas, V., Casimiro, C., Casimiro, W., \& Pasquel, L. (2017). Las representaciones sociales y el discurso noticioso de la Ley Universitaria - Perú. Comuni@cción, 8 (2), 94-104.

Canales, M. (2006). Metodologías de investigación social. Introducción a los oficios. Santiago: LOM Ediciones.

Castañeda, G., Narváez, M., \& Calvache, O. (2017). Conocimientos, oportunidades y barreras para participar en políticas de apoyo a la juventud. Revista de Ciencias Sociales (RCS), 23 (2), 41-51.

Castro-Gómez, S. (2007). Decolonizar la Universidad. La hybris del punto cero y el diálogo de saberes. In El giro decolonial. Reflexiones para una diversidad epistémica más allá del capitalismo global (pp. 79-91). Siglo del Hombre Editores.

Centro de Desarrollo de la OCDE. (2017). Estudio de bienestar y políticas de juventud en el Perú, Proyecto OCDE-UE Inclusión juvenil. www.oecd.org/dev

Chirinos, M. (2017). La Gerencia como fenómeno y la Complejidad. Sistemas y conexiones. Utopía y Praxis Latinoamericana. Revista Internacional de Filosofía Iberoamericana y Teoría Social, 78 (22).

Criado, E. M. (1992). El grupo de discusión como situación social. Reis, 79 (97), 81-112.

Cruz, M., \& Fuentes, E. (2017). Peasant organization during the Chilean Popular Unity: subaltern memories from the revolutionary militancy, feminine and local. Izquierdas, 
$37,54-93$.

Cubides, H. (2010). Trazos e itinerarios de diálogos sobre política con jóvenes contemporáneos de Bogotá. Nómadas, 32, 59-79.

De Sousa, B. (2011). Epistemologies of the South Boaventura. Utopía y Praxis Latinoamericana. Revista Internacional de Filosofía Iberoamericana y Teoría Social, $16(54), 17-39$.

Delgado-Fernández, S., \& Cazorla-Martín, Á. (2017). The Spanish Socialist Workers' Party: From hegemony to decadence. Revista Española de Ciencia Politica, 44, 247-273. https://doi.org/10.21308/recp.44.10

Díaz, A. (2017). Participación ciudadana en la gestión y en las políticas públicas. Gestión y Política Pública, 26 (2), 341-379.

Díaz, A. (2018). From Limited Participation to Disinformation. Difficult Balances in the Execution of Metro Line 12 in Mexico City. Gestión y Política Pública, 177-224.

Domper Lasús, C. (2018). Francoism through the Polls. Methodology, Sources and Challenges for an Electoral Approach to Franco's Regime. Politica y Sociedad, 55 (1), 115-134. https://doi.org/10.5209/POSO.54803

Driscoll, A. (2017). Bolivia's "Democracy in Transition": more questions than answers in 2016. Revista de Ciencia Política, 37 (2), 255-280.

Dudley, J. (2018). Fundamentos físicos y metafísicos de la ética para Aristóteles. Areté Revista de Filosofia, 30 (1), 7-21. https://doi.org/10.18800/arete.201801.001

Durán, R. (2017). Deleuze, Resnais and Prigogine: The Last Year at Marienbad and Unstable Dynamical Systems. Rev. Filos., Aurora, Curitiba, 29 (46), 51-72. https://doi.org/10.7213/1980-5934.29.046.DS03

Echeverría, R., Castillo, M. T., Evia, N., \& Carrillo, C. (2017). Representaciones sociales de líderes institucionales acerca del juego en casinos mexicanos. Revista de Psicología, 35 (1), 5-30. https://doi.org/10.18800/psico.201701.001

Errejón, I., Espasandín, J., \& Iglesias, P. (2007). The Return of Túpac Katari - Bolivia and Global Transformation Processes of Capitalism. Tabula Rasa, 7, 111-148.

Flores, C. (2017). La representación juvenil en Lima y el reto de la participación paralela. Revista Argumentos, 2, 26-31.

Font, P. (2018). Facticity in Francisco Suárez' political philosophy: a path to another 
Modernity. Pensamiento, 74 (279), 179-200. https://doi.org/pen.v74.i279.y2018.009

Galarreta, R. (2016, May 16). La inclusión política de los jóvenes. 26-27. https://elcomercio.pe/opinion/colaboradores/inclusion-politica-jovenesrene-\%0Agalarreta-205669

García-Espín, P., Ganuza, E., \& De Marco, S. (2017). ¿Asambleas, referéndums o consultas? Representaciones sociales de la participación ciudadana. Revista Española de Investigaciones Sociológicas, (157), 45-64. https://doi.org/10.5477/cis/reis.157.45

García-García, V. (2017). Evaluación de políticas públicas juveniles en tres municipios del Estado de México (2013-2015). Revista Latinoamericana de Ciencias Sociales, Niñez y Juventud, 15 (1), 403-418. https://doi.org/10.11600/1692715x.1512528012016

García-Granero, M. (2017). Nietzsche and Human Enhancement. On the Concept of Life. ISEGORÍA. Revista de Filosofía Moral y Política, 57, 599-615. https://doi.org/10.3989/isegoria.2017.057.09

García, O. (2018). Presence of Neo-fascism in Contemporary European Democracies. Revista Española de Investigaciones Sociológicas, 162, 3-20. https://doi.org/10.5477/cis/reis.162.3

Garrido, C. (2017). El dilema de la democracia en el interior de los partidos. UNED. Teoría y Realidad Constitucional, 40, 317-347.

Gómez, R. (2018). Trust in Congress and Public Opinion: The Mexican Case. Revista Mexicana de Ciencias Políticas y Sociales, 63 (233), 117-140. https://doi.org/10.22201/fcpys.2448492xe.2018.233.59483

Gonzalorena, J. (2017). Problemas y perspectivas actuales del desarrollo económico. Economía UNAM, 14 (41), 110-129. https://doi.org/10.1016/j.eunam.2016.09.001

Grau, J. (2017). Situated Imaginaries: How Audiovisual Analysis Contributes to the Understanding of Adoption. Revista de Dialectología y Tradiciones Populares, 72 (1), 125-146. https://doi.org/10.3989/rdtp.2017.01.005

Guzman, (T.) Y. (2017). Los mecanismos de democracia directa en Cuba: diseño normativo y práctica. Perfiles Latinoamericanos, $25 \quad$ (50), 103-127. https://doi.org/10.18504/p12550-006-2017

Hernández, A., \& Gimate-Welsh, A. (2018). The Legislative Debate on the Electoral Threshold in the 2013-2014 Political-Electoral Reform. Revista Mexicana de 
Ciencias Politicas $\quad y \quad$ Sociales, $63 \quad$ (232), 17-44. https://doi.org/10.22201/fcpys.2448492xe.2018.232.59325

Herrera, K. (2017). Las organizaciones de base de Alianza Pais: el papel de los comités de la revolución ciudadana en la movilización política. Análisis Político, 91, 96-109.

Hidalgo, R., Alvarado, V., Santana, D., \& Paulsen, A. (2018). Metaspace: The cosmopolitan skin of an invented environment. Representations about Barrio Italia, Santiago de Chile. Estudios Demográficos y Urbanos, 33 (97), 79-110. https://doi.org/10.24201/edu.v33i1.1728

Huanca-Arohuanca, J. W. (2019). El despertar de una nueva era: colonización y camino hacia la revolución. Revista Revoluciones, 1 (1), 1-3. http://revistarevoluciones.com/index.php/rr/article/view/1/2

Huanca-Arohuanca, J. W. (2020a). Caleidoscopio social al Covid-19: pánico y desesperación en tiempos de aislamiento. Revista Universidad y Sociedad, 12 (6), 226-231. https://rus.ucf.edu.cu/index.php/rus/article/view/1836

Huanca-Arohuanca, J. W. (2020b). Contrahegemonía y la lucha por la educación en el sur del Perú. Editorial Académica Española.

Huanca-Arohuanca, J. W. (2020c). Retropías y distopías de la educación en Puno. Revista Helios, 4 (1), 270-271. https://doi.org/10.22497/Helios.41.4116

Huanca-Arohuanca, J. W. (2021). Narrativas de guerra y resistencia: participación de la mujer austral del Perú en la Guerra del Pacífico. Encuentros. Revista de Ciencias Humanas, Teoría Social y Pensamiento Crítico, 13, 50-59. https://doi.org/http://doi.org/10.5281/zenodo.4395218

Huanca-Arohuanca, J. W., Canaza-Choque, F. A., \& Flores, E. (2020). El dolor de los subalternos y el deseo de una revolución inconclusa: Narrativas sobre la violencia política en la Nación Aymara - Perú.Comuni@cción: Revista De Investigación En Comunicación y Desarrollo, 11 (2), 177-189. https://doi.org/10.33595/22261478.11.2.436

Huanca-Arohuanca, J. W., \& Geldrech, P. (2020). Planificación educativa y gestión pedagógica-estratégica-operacional en las instituciones del nivel inicial en el sur del Perú. Revista Conrado, $16 \quad$ (76), 369-376. https:/conrado.ucf.edu.cu/index.php/conrado/article/view/1497 
Huanca-Arohuanca, J. W., \& Núñez, L. (2020). Estimaciones y contrastes de la pandemia en Perú y en el contexto mundial. Educare Et Comunicare. Revista Científica de La Fcultad de Humanidades, 8 (2), 10-20. https://doi.org/10.35383/educare.v8i2.440

Huanca-Arohuanca, J. W., \& Pilco, N. (2021a). Acciones revolucionarias en Ámérica Latina: Puno y el Alto Perú durante el proceso de independencia (1809-1825). Chakiñan. Revista de Ciencias Sociales y Humanidades, 14. https://doi.org/10.37135/chk.002.14.05

Huanca-Arohuanca, J. W., \& Pilco, N. (2021b). Transición del virreinato a la República: caleidoscopio sociopolítico-económico del altiplano puneño en la Independencia de Perú (1815-1825). Diálogo Andino, 65, 379-391. http://dialogoandino.cl/wpcontent/uploads/2021/07/28-HUANCA-PILCO-RDA-65.pdf

Huanca-Arohuanca, J. W., Supo-Condori, F., Sucari, R., \& Supo, L. A. (2020). El problema social de la educación virtual universitaria en tiempos de pandemia, Perú. Revista Innovaciones $\quad$ Educativas, $\quad 22, \quad 115-128$. https://doi.org/10.22458/ie.v22iespecial.3218

Jodelet, D. (1986). La representación social: fenómenos, concepto y teoría. Psicología Social. Barcelona: Paidós.

Korstanje, M. E. (2009). Theorstein Veblen, Jacques Derrida y Slavoj Zizek: religión, hospitalidad y modernidad. Bajo Palabra. Revista de Filosofía, 4, 33-46.

Laitano, G. (2018). The prison government in the last Argentinean civil-military dictatorship: the political women prisoners experience (Villa Devoto, 1975-1981). Izquierdas, 1 (38), 1-22.

López, M. C. (2018). Herbert Marcuse: "El final de la utopía” en el siglo XXI. Daimon. Revista Internacional de Filosofía, 74, 71-88. https://doi.org/10.6018/daimon/266491

Lorente, J., \& Sánchez-Vítores, I. (2018). Disaffection at the Ballot Box : The 2015 General Election in Spain. Revista Española de Investigaciones Sociológicas, 161, 41-62. https://doi.org/10.5477/cis/reis.161.41

Lorenzano, S. (2018). Ruin upon Ruin. Revista Mexicana de Ciencias Políticas y Sociales, 63 (234), 431-434. https://doi.org/10.22201/fcpys.2448492xe.2018.234.65864

Lores, F., \& Jociles, M. (2018). What Do Experts Mean When They Speak about Culture? 
Revista de Dialectología y Tradiciones Populares, 73 (1), 87-105. https://doi.org/10.3989/rdtp.2018.01.003

Mansilla, M., \& Piñones-Rivera, C. (2017). Lo moreno es bello. Componentes identitarios de las mujeres jóvenes evangélicas aymaras. Revista Latinoamericana de Ciencias Sociales, Niñez y $\quad$ Juventud, $15 \quad$ (2), 1005-1019. https://doi.org/10.11600/1692715x.1521429082016

Manzano, V. (2018). El psicobolche: juventud, cultura y política en la Argentina de la década de 1980. Izquierdas, 2 (41), 250-275.

Misses-Liwerant, J. B., \& Saracho, F. J. (2018). Los 68: movimientos estudiantiles y sociales en un emergente transnacionalismo y sus olas dentro del sistema-mundo. A manera de editorial. Revista Mexicana de Ciencias Políticas y Sociales, 63 (234), 13-52. https://doi.org/10.22201/fcpys.2448492xe.2018.234.65866

Monsiváis-Carrillo, A. (2018). El apoyo a la democracia en México ¿El deseo crítico de una democracia liberal? Política y Gobierno, 25 (2), 263-300.

Mora, E., Pujal i Llombart, M., \& Albertín, P. (2017). The gender vulnerability contexts of chronic pain. Revista Internacional de Sociología, 75 (2), 1-12. https://doi.org/10.3989/ ris.2017.75.2.15.60

Mora, M. (2002). La teoría de las representaciones sociales de Serge Moscovici. Athenea Digital, 2, 1-25.

Morales, M., \& Reveco, B. (2018). El efecto de las generaciones políticas sobre la participación electoral. El caso de Chile, 1999-2013. Perfiles Latinoamericanos, 26 (52), 1-27. https://doi.org/10.18504/p12652-011-2018

Moscovici, S. (1961). El psicoanálisis, su imagen y su público. Buenos Aires: Huemul.

Muñoz, V., \& Durán, C. (2019). Los jóvenes, la política y los movimientos estudiantiles en el Chile reciente. Ciclos sociopolíticos entre 1967 y 2017. Izquierdas, 1 (45), 129159.

Netzahualcoyotl-Netzahual, M.-Á. (2015). Las representaciones sociales de los docentes sobre la Reforma Integral de la Educación Básica. Revista Iberoamericana de Educación Superior, 6 (15), 3-25. https://doi.org/10.1016/S2007-2872(15)30001-9

Nunes, F., \& Ranulfo, C. (2017). Impeachment, political crisis and democracy in Brazil. Revista de Ciencia Política, 37 (2), 281-304. 
Oficina Nacional de Procesos Electorales (ONPE). (2017). Participación política de la juventud en las Elecciones Generales 2016. www.onpe.gob.pe

Ortiz, P. (2018). La construcción del discurso político del emprendimiento en España. Realidad e ideología. Papers, $103 \quad$ (2), 229-253. https://doi.org/10.5565/rev/papers.2368

Osorio, L. (2018). Business and power in Zulia during gomecism. Revista de Ciencias Sociales (RCS), 24 (2), 94-104.

París, S. (2018). El reconocimiento recíproco en la filosofía de Axel Honneth: contribuciones a la transformación pacífica de los conflictos. Pensamiento, 74 (280), 369-385. https://doi.org/pen.v74.i280.y2018.003

Pérez, J. A. (2018). Philosophy in the Face of the Serious Pathology of the Patriarchal Order. Utopía y Praxis Latinoamericana. Revista Internacional de Filosofía Iberoamericana y Teoría Social, 23 (80), 93-105.

Polo, J., \& Piñeiro, E. (2019). Ciencia moderna, planeta torturado. Una reflexión crítica sobre el modo eurocéntrico de conocer la naturaleza e intervenir en el medio ambiente. Izquierdas, 46, 194-217.

Radic, J. (2018). Entre la esperanza y la desilusión: memorias de la lucha por la democracia en las poblaciones de Santiago (1983-1988). Revista Austral de Ciencias Sociales, $34,117-137$.

Ramos-Galarza, C., Apolo-Buenaño, D., \& Jadán-Guerrero, J. (2018). Jóvenes y política: una revisión de estudios desde latinoamerica. Observatorio (OBS*) Journal, 1, 169-182.

Ravelo-Medina, M., \& Radovic-Sendra, Y. (2018). Representaciones de lo político en estudiantes secundarios en Santiago de Chile: resignificando el sentido de la formación ciudadana. Revista Latinoamericana de Ciencias Sociales, Niñez y Juventud, 16 (1), 389-402. https://doi.org/10.11600/1692715x.16124

Revilla, J. (2017). Reconstructions of Labour Identity in Unlivable Organizational Contexts. Politica y Sociedad, 54 (1), 65-86. https://doi.org/10.5209/POSO.51718

Rincón, A. (2018). De la esperanza a nuevas incertidumbres. Sobre la distribución de la votación en el plebiscito colombiano (2016). Análisis Político, 92, 137-158.

Rodríguez-Santero, J., García-Carpintero, M. Á., \& Porcel, A. M. (2017). Los estilos de amor en estudiantes universitarios. Diferencias en función del sexo-género. Revista 
Internacional de Sociología, $\quad 75 \quad$ (3), $\quad$ 1-13. https://doi.org/10.3989/ris.2017.75.3.15.171

Rodríguez, D. (2017). Redes sociales y participación política juvenil. https://www.enfoquederecho.com/2017/07/04/redes-sociales-y-participacionpolitica-juvenil/

Romero, K. (2017). Production Conditions of a kidnapping-testimonial literature boom in Colombia. Rev. Colomb. Soc., $41 \quad$ (1), 161-186. https://doi.org/10.15446/rcs.v40n1.61957

Rubio, M. (2013). Para conocer la Constitución de 1993 (Cuarta edi). Metrocolor S.A.

Rubio, M. J. (2019). The Revolutionary Communist Party and the definition of a historical interpretation in its formative period (1967-1987). Izquierdas, 46, 137-161.

Samamé, L. (2017). Carácter adquirido, autodominio y moralidad: hacia una mirada comprehensiva de la filosofía práctica schopenhaueriana. Areté Revista de Filosofía, 29 (1), 125-145. https://doi.org/10.18800/arete.201701.005

Sandoval, J., \& Carvallo, V. (2017). Discourses on politics and democracy by Chilean students from different youth organizations. Revista Española de Ciencia Política, 43, 137-160. https://doi.org/10.21308/recp.43.06

Santos, J. (2018). Una moral de la opacidad: Hume y la virtud del ocultamiento. ISEGORÍA. Revista de Filosofía Moral y Política, 58, 55-76. https://doi.org/10.3989/isegoria.2018.058.03

Secretaría Nacional de la Juventud. (2015). Informe nacional de las juventudes en el Perú 2015. CD Copia S.A.C.

Serrafero, M. D. (2018). Max Weber and the Plebescitarian Democracy. Revista Internacional de Sociología, $\quad 76 \quad$ (2), $1-13$. https://doi.org/10.3989/ris.2018.76.2.16.01630

Sintomer, Y. (2017). Sorteo y política: ¿de la democracia radical a la democracia deliberativa? Daimon. Revista Internacional de Filosofia, 72, 25-43. https://doi.org/10.6018/daimon/295531

Soto, J., \& Visa, M. (2017). Representing Youth Migration. Comparative Study of Its Symbolic Imaginary on Television and Digital Social Networks. Revista de $\begin{array}{llllll}\text { Dialectología } & y & \text { Tradiciones } & \text { Populares, } & 72 & \text { (1), }\end{array}$ 
https://doi.org/10.3989/rdtp.2017.01.001.04

Torres, C., \& Lobera, J. (2017). El declive de la fe en el progreso. Posmaterialismo, ideología y religiosidad en las representaciones sociales de la tecnociencia. Revista Internacional de Sociología, $\quad 75 \quad$ (3), $\quad$ 1-13. https://doi.org/10.3989/ris.2017.75.3.16.61

Trujillo, H., Alonso, F., Cuevas, J., \& Moyano, M. (2018). Evidencias empíricas de manipulación y abuso psicológico en el proceso de adoctrinamiento y radicalización yihadista inducida. Revista de Estudios Sociales, 66, 42-54. https://doi.org/10.7440/res66.2018.05

Urrutia, A. (2018, August 22). Juventud y participación electoral. https://elperuano.pe/noticia-juventud-y-participacion-electoral-70357.aspx

Van Dijk, T. (1996). Análisis del discurso ideológico. Versión, 6, 15-43.

Vargas, V., Leal, M., \& Hernández, C. (2018). Public agenda for the financing of information systems in organizations of the health sector. Revista de Ciencias Sociales (RCS), 24 (2), 105-113.

Villavicencio-Caparó, E., \& Alvear-Córdova, M. C. (2017). Epistemology of the southern hemisphere and dentistry. Revista Odontológica Mexicana, 21 (4), 226-228. https://doi.org/10.1016/j.rodmex.2018.01.001

Zarta, P. (2018). La sustentabilidad o sostenibilidad: un concepto poderoso para la humanidad. Tabula Rasa, 28, 409-423. https://doi.org/10.25058/20112742.n28.18

Zumárraga, M., Reyes, C., \& Carofilis, C. (2017). ¿Verdad o ficción? el uso político de las redes sociales en la participación política Offline en las elecciones presidenciales en Ecuador. Análisis Político, 91, 130-145. 